\title{
El diseño inteligente, la teoría de la evolución y el ateísmo.
}

\section{Intelligent design, evolutionary theory and atheism.}

\author{
Luis Enrique Ortiz Gutiérrez* \\ Departamento de Filosofía / Universidad de Guadalajara (MÉXICO) \\ CE: luiseo@yahoo.com
}

DOI: $\underline{10.32870 / \text { sincronia.axxiii.n76.3b19 }}$

\begin{abstract}
CC) $\mathrm{BY} \cdot \mathrm{NC}$
Esta obra está bajo una Licencia Creative Commons Atribución-NoComercial 4.0 Internacional
\end{abstract}

\begin{abstract}
* Profesor de tiempo completo asistente C adscrito al Departamento de Filosofía, del Centro Universitario de Ciencias Sociales y Humanidades (CUCSH), de la Universidad de Guadalajara. Cuenta con Reconocimiento Perfil PRODEP (20152018; 2018-2021), y es miembro del Cuerpo Académico de Retórica, Lógica y Teoría de la Argumentación. Sus líneas de investigación son epistemología, filosofía de la ciencia, argumentación y lingüística. En la actualidad, imparte los cursos de Filosofía de la Biología, Seminario de Descartes, Filosofía de la Cultura y Teoría de Argumentación en la Licenciatura en Filosofía, y de Epistemología en la Maestría en Estudios Filosóficos, ambas adscritas al Departamento de Filosofía. Correo electrónico: luiseo@yahoo.com
\end{abstract}

Recibido: $16 / 01 / 2019$

Revisado: $21 / 02 / 2019$

Aprobado: $12 / 03 / 2019$

\section{RESUMEN}

El conocimiento ha avanzado considerablemente en su intento de explicar el mundo natural sin recurrir a entidades sobrenaturales. Esto ha llevado a entrar en conflicto, ocasionalmente, con ciertos credos religiosos. En especial, la teoría de la evolución ha sucitado fuertes discusiones entre científicos y teólogos acerca de la existencia de Dios. Pero también han surgido intentos, al interior de la ciencia, de recurrir a esta teoría para justificar el ateísmo. El presente escrito tiene la finalidad de explorar estas polémicas metafísicas. 
Ante este problema, mi propuesta es que un agnosticismo ateo es la postura que está en conformidad con el naturalismo de la ciencia contemporánea.

Palabras clave: Ciencia. Biología evolutiva. Diseño inteligente. Ateísmo. Agnosticismo.

\begin{abstract}
:
Scientific knowledge has advanced considerably in its attempt to explain the natural world without resorting to supernatural entities. This has led her to enter into conflict, occasionally, with certain religious beliefs. In particular, the theory of evolution has produced strong arguments among scientists and theologians about the existence of God. But there have also been attempts by some scientists to resort to this theory to justify atheism. The present paper has the purpose of exploring these metaphysical polemics. Faced with this problem, my proposal is that an atheist agnosticism is the position that is in accordance with the naturalism of contemporary science.
\end{abstract}

Keywords: Sciencie. Evolutionary biology. Intelligent Design. Atheism. Agnosticism.

Hay una célebre anécdota en la historia de las ciencias, que relata que cuando el astrónomo Laplace presentó su obra El Sistema del Mundo al emperador Napoléon, éste le preguntó qué lugar tenía Dios en su cosmología. Laplace le respondió contundente: "Sire, je n'ia pas besoin de cette hypothèse" ("Su Majestad, no he necesitado de esa hipótesis") (citado en Koyré, 2005 p. 255).

Hasta hace unos decenios atrás, el concepto de Dios jugaba un papel importante en las discusiones científicas y filosóficas acerca de la Naturaleza. Las leyes físicas, que comenzaban a ser descritas matemáticamente con una asombrosa exactitud, eran consideradas como una clara evidencia de la magnificencia de Dios. El orden matemático del mundo era visto como el sello de la Creación. Pero hacia el siglo XIX la situación cambió a tal punto que la apelación a la divinidad se 
hacía innecesaria. Y es en esta época cuando un naturalista inglés de nombre Charles Darwin pone en jaque a la teología natural.

Las ciencias han avanzado desde entonces, proporcionándonos un abanico de teorías acerca del origen del Cosmos y de la vida. La nueva astrofísica, las teorías cuánticas y la biología evolutiva parecen desentrañar, poco a poco, muchas incógnitas que en el pasado eran reservadas para el Creador. En este sentido, el desarrollo de la ciencia parece confirmar la postura de Laplace hacia la "hipótesis Dios": las explicaciones científicas formulan una serie de conjeturas e inferencias centradas dentro de los límites del naturalismo ${ }^{1}$, sin recurrir a ninguna clase de explicación teológica o sobrenatural. No obstante, muchos científicos son tentados por la especulación metafísica, cuando intentan dar cuenta de las causas primeras de la Naturaleza, cuando se aventuran más allá de toda experiencia posible.

Pero en los asuntos metafísicos no se ha avanzado ni un ápice; las viejas polémicas de la filosofía natural en torno a un Universo resultado del azar o de la planeación de alguna entidad superior siguen tan vivas y tan inciertas como lo eran en los siglos XVII-XVIII. Y es aquí donde surge la gran pregunta: del hecho de que la "hipótesis Dios" no tenga cabida en las explicaciones naturalistas de las ciencias actuales, ¿se sigue la negación de la existencia de Dios? Muchos científicos contemporáneos asumen que la respuesta es afirmativa. En tiempos recientes, un grupo de teóricos que encabezan Richard Dawkins, Sam Harris y Daniel Dennett, defienden y promueven un ateísmo militante que no se circunscribe únicamente al campo científico. Tomando a Darwin como bandera, Dawkins y compañía asumen que el desarrollo de la ciencia nos da ciertas pautas para afirmar no sólo que la "hipótesis Dios" es inútil, sino hasta perniciosa para la investigación científica.

En especial, el debate acerca de la "hipótesis Dios" se ha tornado muy acalorado en el tema de la evolución biológica. Se trata de un conflicto que se remonta hasta los tiempos de Darwin y que

\footnotetext{
${ }^{1}$ Por "naturalismo" entiendo lo que en la clasificación de Glock (2012) se denomina "naturalismo ontológico" (la negación de que haya un mundo sobrenatural, no gobernado por las leyes físicas), aunque en mi caso, propongo una versión débil, que establecería la posibilidad de que sólo existe el mundo físico. Desde esta postura, la apelación a entidades trascendentes (Dios, el alma, etc.) así como explicaciones particulares para estas entidades (intuiciones intelectuales, explicaciones teleológicas, etc.) sería innecesaria para la ciencia.
} 
en el presente sigue suscitando las mismas pasiones; curiosamente, en este debate se recurre, en muchos casos, a los mismos argumentos de antaño. Mas el problema central se mantiene en pie: ¿se deriva el ateísmo como consecuencia necesaria de la aceptación de la teoría de la selección natural? ¿O es compatible con la idea de un Ser Supremo? ¿Es posible responder, con algún grado de certeza, a estas preguntas?

En el presente texto, analizaré esta polémica presentando algunos argumentos tanto de los defensores del llamado "Diseño Inteligente" (DI), como del ateísmo militante de Dawkins y sus seguidores. En cuanto al primero, analizaré algunos de sus argumentos centrales para mostrar que no están justificados, y que el DI no representa una verdadera alternativa frente al actual programa de investigación de la biología evolutiva. En cuanto al segundo, problematizaré la idea de que el ateísmo se sigue necesariamente del darwinismo, a la vez presentaré una posible solución al problema con sus respectivos argumentos. Mi propuesta, en este sentido, es que un agnosticismo ateo sería la postura más acorde al espíritu naturalista que orienta a la investigación científica.

Previamente, presentaré un breve resumen de la teoría de la selección natural, para entender sus alcances explicativos, sus implicaciones filosóficas y sus consecuencias. Remontándonos al origen de la discusión, podemos entender su estado presente.

\section{De la Creación a la Evolución.}

Como señalé antes, hasta el siglo XVIII, la ciencia, la metafísica y la teología no estaban en conflicto, sino que convivían con cierta armonía. El orden del mundo que revelaba la física atestiguaba la magnificencia del Creador. Así, la teología natural representaba, en muchos casos, la consecuencia última de la reflexión filosófica y científica sobre la Naturaleza.

La pérdida de la armonía comenzó en la llustración, cuando algunos pensadores se percataron de que, mientras la ciencia daba resultados contrastables, no ocurría lo mismo con la teología y la metafísica. Muchos filósofos cuestionaron la pertinencia de las especulaciones metafísicas como consecuencia de las explicaciones científicas. Por ejemplo, David Hume formuló una crítica mordaz contra estas pretensiones: 
Si procediéramos a revisar las bibliotecas convencidos de estos principios, iqué estragos no haríamos! Si cogemos cualquier volumen de teología o metafísica escolástica, por ejemplo, preguntemos: ¿Contiene algún razonamiento abstracto sobre la cantidad y el número? No. ¿Contiene algún razonamiento experimental acerca de cuestiones de hecho o existencia? No. Tírese entonces a las llamas, pues no puede contener más que sofistería e ilusión (Hume, 1988: 209).

Posteriormente, Immanuel Kant en su Crítica de la Razón Pura (2009) sostuvo la imposibilidad de la metafísica como ciencia, bajo el argumento de que esta disciplina se basa en el uso especulativo de la razón que deriva en contradicciones. Posteriormente, el positivismo y las doctrinas materialistas, ya en el siglo XIX, desterraron completamente a la metafísica y la teología del campo de la física.

Pero en el terreno de la biología la teología natural permaneció relativamente inmune a las críticas de los ilustrados. William Paley, en su Teología Natural (1802), concluía que la complejidad de los organismos vivientes no podía explicarse sino como resultado de un proyecto inteligente. Su analogía es ya célebre en la historia de las ideas: así como un reloj, con su finísimo sistema de engranes perfectamente empalmados, gracias al cual puede cubrir la función de marcar la hora, no puede ser resultado de causas fortuitas, el Universo entero, con sus bellas y complejas formas, tampoco puede ser resultado de la casualidad. Las ideas de Paley y otros teólogos gozaban de amplia aceptación, y sus detractores, aunque podían objetar la validez de sus argumentos, carecían de una explicación alternativa satisfactoria.

Si bien las críticas de Hume y Kant ya hacían temblar el edificio de la teología natural, la publicación del Origen de las Especies (2010) de Darwin sería un golpe devastador. Pues si bien aquellos cuestionaban la validez lógica de los argumentos teológicos, Darwin presentaba una teoría científica alternativa que sentaba las bases para una explicación naturalista del origen de la vida, que prescindía por completo de toda apelación a un Ser Supremo.

Pero el impacto de la evolución se presentó en la historia natural, en primera instancia. Al señalar que las especies vivientes están sujetas al cambio evolutivo, dejó sin fundamentos las creencias, hasta entonces aceptadas, acerca de las especies como categorías fijas de la Naturaleza. 
Desde luego, Darwin no es el primero en hablar de evolución; antes que él Buffon, Lamarck y otros naturalistas (incluido su abuelo, Erasmus Darwin) ya habían formulado esbozos de teorías evolutivas. La originalidad de Charles Darwin radica en haber propuesto una teoría capaz de esclarecer el proceso de transformación de las especies: la selección natural.

Darwin observó que hay una tendencia natural en las especies a producir pequeñas variaciones en el curso de las generaciones ${ }^{2}$. Aunque no supo describir con precisión en qué consistía esa tendencia -aunque identificó a la reproducción como un factor determinante-, ni cómo se transmitían los viejos y los nuevos caracteres en las siguientes generaciones, el científico inglés entendió que esas pequeñas diferencias eran cruciales para la supervivencia en determinados ambientes. Apreció que esas variaciones podrían ser benéficas o no, y en este sentido, la selección natural actúa como un "test de prueba" para discriminar los cambios que resultan ventajosos de los que no lo son. Los organismos con cambios benéficos podrán multiplicarse y trazar nuevos linajes, que en la medida en que se distancien de sus antecesores, llegarán a conformar nuevas especies. Los cambios perjudiciales o la incapacidad para adaptarse, llevarán a la extinción.

Desde la publicación de El Origen de las especies hasta el presente, la teoría se ha enriquecido considerablemente. Gracias a la genética de poblaciones, se ha podido explicar el proceso de variación y transmisión de los caracteres de los organismos. La teoría de la selección natural en su forma actual, la Síntesis Moderna, explica el proceso evolutivo a partir de mutaciones y recombinaciones genéticas, que son sujetas a las pruebas de la selección (Mayr, 1992). En la actualidad, la biología evolutiva conforma un vasto complejo de investigaciones que integran la genética, la anatomía comparada, la zoología, la botánica, la biología molecular, la paleontología, entre otras.

El panorama que la biología evolutiva nos ofrece es el siguiente: la evolución de las especies estaría determinada tanto por la tendencia a la variación como por la selección natural. En otras palabras, el azar y la necesidad: las pequeñas variaciones, como resultado de las recombinaciones genéticas, son fortuitas, pero el "test de prueba" de la selección natural se aplica por igual a todo

\footnotetext{
${ }^{2}$ Para la exposición de la teoría de la selección natural, me baso en Nowinski (1979), Sagan y Druyan (1993) y Price (2010).
} 
organismo y a toda población. En suma, la clave para explicar el cambio evolutivo parece estar en la interacción entre el material hereditario y el entorno.

Sin duda, la teoría aún presenta grandes lagunas. Se desconocen muchos de los pormenores del proceso evolutivo. Y existen fuertes polémicas acerca del factor o los factores que determinan las transformaciones (Eldredge, 1997). Pero es pertinente aclarar que no es la evolución como tal la que es objeto de polémica para los biólogos actuales, sino cómo se ha dado el cambio evolutivo.

Fuera del contexto de la ciencia, la teoría de la evolución ha traído importantes consecuencias. Su impacto es equiparable al de la revolución copernicana en el siglo XVI. Si Copérnico y Galileo dejaron sin sustento la vieja idea de la Tierra como centro del Universo, con Darwin el hombre dejó de ser "el Rey de la Creación", siendo desde ahora una especie animal más, pariente cercano de los primates y remoto de los monos. Este es uno de los puntos que justamente ha generado mayor rechazo por parte de los círculos religiosos ${ }^{3}$.

Aquí se pueden apreciar las consecuencias de esta teoría para la teología natural: siendo la variación en gran medida azarosa, parece no dejar lugar a ninguna clase de diseño o planeación preexistente. La metáfora darwiniana representa a la vida avanzando por tanteos, conservando formas y desechando otras. De igual modo, si se habla de finalidad, se entiende como una función adaptativa: los flagelos de los microorganismos, las branquias de los peces, la estructura ósea de los depredadores, las células fotosintéticas de las plantas, los rituales de apareamiento de las aves, etc., responden a las necesidades de adaptación al medio (Cronin, 1991). No parecen responder a ninguna clase de propósito divino. No hay lugar para la explicación teleológica 4 .

\footnotetext{
${ }^{3}$ El tema de la ascendencia de la especie humana ha generado uno de los argumentos más antiguos de los creacionistas: "si el hombre desciende del mono, ¿por qué hay monos todavía?" Un argumento que evidencia el desconocimiento de lo implica la ascendencia común. En ningún momento se enuncia que el hombre descienda directamente de los monos, sino que ellos y nosotros provenimos de un mismo tronco común. La confusión radica en suponer que la evolución traza una línea recta, cuando se trata, en realidad, de una ramificaciones con múltiples líneas.

${ }^{4} \mathrm{Sin}$ duda, el asunto de la pertinencia de las explicaciones teleológicas en las ciencias ha generado mucha controversia en la filosofía de la biología (véase Ruse, 1990). Monod (1981) propuso a la teleonomía o finalidad adaptativa como un rasgo distintivo de la vida, mientras que Maturana y Varela (1994) la consideran un concepto prescindible. Dado que es un tema que merece un tratamiento más amplio, no me adentraré en esta discusión por ahora, y para efectos de exposición, partiré de la distinción entre teleonomía como la finalidad de estructuras y funciones no establecida o guiada por un agente intencional, y teleología como finalidad establecida y guiada por un agente intencional. Claro está, la cuestión está lejos de estar resuelta.
} 
En este tenor, la teoría de la selección natural opera bajo las premisas del naturalismo pues busca las claves de la evolución en causas naturales: secuencias de ADN, cruzas e hibridaciones, interacción con el medio, datación de fósiles, desplazamiento y aislamiento de poblaciones, etc. Por tanto, la biología evolutiva no tiene necesidad de invocar fuerzas sobrenaturales para explicar el origen de la vida y aunque todavía se presentan muchas incógnitas y "cajas negras", los avances conseguidos fundan cierta confianza en la explicación de la vida en términos netamente naturalistas. De ahí que surja la pregunta acerca de si la apelación a la teología sea relevante. Pero también es pertinente preguntar si la negación de la existencia de un Diseñador o Creador es una consecuencia necesaria del darwinismo.

Desde luego, no es posible establecer un juicio adecuado sobre este punto, sino se toma en consideración las posturas antagónicas. Por ello, es necesario considerar si la aceptación de la evolución de la vida conlleva necesariamente un rechazo de cualquier teología, lo que nos obliga a revisar las propuestas de aquellos que, sin desechar la ciencia como tal, se niegan a adoptar el enfoque naturalista propio de la biología evolutiva. Como el último recurso de los defensores del Relojero Perfecto de Paley, el Diseño Inteligente se pretende situar como una teoría rival de la selección natural. Veremos enseguida si tal pretensión está justificada, lo que significa, de ser así, la participación de la metafísica y la teología al interior de la ciencia.

\section{La marca del Diseño.}

En el fondo, la controversia acerca de la evolución, desde la segunda mitad del siglo XIX hasta el presente, ha estado marcada por la aceptación o el rechazo de un Ser Supremo que crea y ordena el mundo natural. En este sentido, gran parte de la reacción contra la teoría de la evolución se basa en la defensa de los textos sagrados. Se trata del creacionismo "literalista", para el que la lectura literal del Génesis bíblico es incuestionable.

Hay otras formas de creacionismo que no mantienen una actitud tan hostil hacia la ciencia, aunque rechazan el enfoque naturalista adoptado por la teoría de la selección natural. El neocreacionismo, cuya tendencia más conocida es la que defiende el Diseño Inteligente (DI), 
representa un programa pretendidamente científico que, según sus defensores, refuta las actuales teorías evolutivas. Un aspecto importante es que los defensores del DI no se pronuncian por la teología explícitamente; más aún, no hay ninguna afirmación acerca de la naturaleza del diseñador. Esto lo retomaré más adelante.

En primera instancia, hay que señalar que los detractores del DI descartan esta teoría por no cubrir los requisitos metodológicos básicos de la ciencia (Dennett, 2007; Pievani, 2009). Otras razones que se aducen en su contra es el hecho de que el DI obedece a motivaciones religiosas (o incluso políticas), y sus promotores subrepticiamente reciben financiamiento de grupos e instituciones de este tipo. Esto último puede ser cierto, pero es falaz desechar esta teoría a partir de las inclinaciones o las creencias de sus sustentantes. Por ello, hay que analizar su propuesta y sopesar sus razones; aclarando, claro está, que tal análisis no deja de ser crítico.

En primer lugar, parece haber un denominador común en la negativa de los creacionistas, sean literalistas o impulsores del DI, de aceptar la teoría de la selección natural. Este denominador común es el rechazo del factor del azar: a los creacionistas les resulta impensable que los organismos y los procesos naturales sean resultado de causas fortuitas. Aquí no han avanzado más allá de Paley, si bien disponen de argumentos aparentemente más elaborados. La forma que subyace a muchos de los argumentos del DI es la siguiente:

1. Todo orden es resultado de la acción de un ser inteligente.

2. La Naturaleza muestra orden.

3. Por tanto, la Naturaleza es resultado de la acción de un ser inteligente.

Este argumento, que remite a la vieja teología medieval, es reformulado con expresiones tomadas de las ciencias o adornado con recursos probabilísticos ${ }^{5}$. La clave del argumento radica en la premisa que establece la relación de implicación entre orden y diseño (y más específicamente, diseño inteligente): "si hay orden, éste debe ser resultado de un diseño previo". Como el reloj de

\footnotetext{
${ }^{5}$ Este es otro detalle importante: los defensores del DI intentan evitar la jerga metafísica o teológica, haciendo uso del léxico científico o pretendidamente científico.
} 
Paley, las complejas formas de los organismos vivientes no pueden ser resultado del azar. Tal es la tesis básica del DI.

Michael Behe (2004) formula una versión de este argumento, mediante su concepto de "complejidad irreductible". Ésta es una característica, según el bioquímico estadunidense, de los sistemas organizados: la relación entre los componentes de un sistema es tan estrecha para su funcionamiento que, al restarse uno de ellos, éste se colapsa (de ahí el término "irreductibilidad"). A partir de esto, Behe señala que tales sistemas no podrían haber evolucionado por la acumulación de partes aisladas, y por tanto, es altamente improbable que ocurra por azar. De ello infiere que tal sistema sólo puede ser resultado de un diseño inteligente.

Pero este argumento carece de peso. En primera instancia, el salto de la premisa "un sistema complejo es altamente improbable" a "un sistema complejo es resultado de un diseño", no está justificada en modo alguno. Behe no considera otras alternativas, como el hecho de que la complejidad y el orden puedan emerger a partir de sistemas caóticos -como lo ilustran las "estructuras disipativas" de llya Prigogine-. Un claro ejemplo se halla en los experimentos del físico Henri Bénard, en cuyos experimentos pudo producir estructuras hexagonales en una capa de líquido, sometiéndolo a un flujo constante de calor. Ninguno de estos fenómenos es resultado de un diseño previo, sino de la convergencia de distintos procesos físicos. Por tanto, no es condición necesaria que un sistema complejo sea resultado de una acción planificada.

Aun planteando la cuestión en términos de probabilidades, como lo sugiere la tesis de Behe ("la alta complejidad es improbable") se elimina de antemano todo el abanico de opciones posibles. El autor parece confundir 'improbabilidad' con 'imposibilidad'. Supongamos que tenemos un recipiente con 200 bolas, 199 de color blanco y 1 de color negro. Como podemos ver, es muy improbable extraer la bola negra en unas cuantas jugadas, pero no imposible. Lo que resultaría imposible, en todo caso, sería extraer una bola de otro color habiendo sólo blancas o negras en el recipiente. Como bien saben los matemáticos, el incremento de jugadas reduce la improbabilidad.

Por otro lado, el autor asume de antemano que las jugadas no son acumulativas. Por ejemplo, si en cada jugada se extrae una bola y se deja fuera del recipiente, las probabilidades de 
llegar a la bola negra se incrementan. Así ocurre, de hecho, en el proceso evolutivo, como lo demuestra la genética: los cambios evolutivos conllevan innovación, pero también conservación ${ }^{6}$. La evolución no inicia en ceros en cada jugada, se apoya en las jugadas pasadas. En consecuencia, carece de sentido la correlación entre "alta complejidad" e "improbabilidad".

Dawkins, por su parte, aplica una "vuelta de tuerca" al planteamiento de Behe, con el siguiente contraargumento:

La complejidad organizada es algo con lo que estamos teniendo problemas a la hora de explicarla. Una vez se nos permite postular su existencia, aunque sólo sea la complejidad organizada de la máquina replicadora del DNA/proteína, es relativamente fácil invocarla como generadora de una complejidad organizada aún mayor. (...) Pero cualquier Dios capaz de diseñar algo tan complejo como la maquinaria duplicadora del DNA/ proteína, de una forma tan inteligente, debe de haber sido al menos tan complejo y organizado como la propia máquina (Dawkins, 1993, p. 170).

Como se puede apreciar, se trata de una reducción al absurdo: si la alta complejidad implica improbabilidad, y no hay otra explicación para los sistemas complejos que el ser resultado de la acción de un Diseñador, éste tiene que ser por fuerza tan o más complejo que el sistema que produce. Pero si partimos de la premisa antes formulada, hemos de concluir que el Diseñador, al ser altamente complejo, es también improbable.

De igual manera, John A. Paulos (2008, p. 125ss) sostiene que argumentos como el de Behe muestran un razonamiento erróneo que asume que "lo mismo causa lo mismo" (similar al de los homeópatas, que plantean que la cura de una enfermedad se logra al inducir los mismos síntomas). En este caso, erróneamente se asume que la complejidad sólo puede ser resultado de algo

\footnotetext{
${ }^{6}$ De esta forma, también pierde sustento una de las objeciones favoritas de los creacionistas: "el ojo humano no pudo evolucionar por azar". Contrario a lo que suponen, los orígenes de nuestro ojo no son una incógnita ya que se puede trazar su genealogía a partir las células fotosensibles de organismos unicelulares, los órganos fotosensibles multicelulares de los gusanos de tierra, "el ojo en copa" de algunos moluscos, y así sucesivamente. Claramente, este proceso muestra acumulación de las formas previas. Por otro lado, parece asumirse, en esa objeción, que el ojo representa una cierto grado de perfección, como si los órganos humanos constituyesen el culmen de la evolución. No comprenden otro aspecto fundamental de la selección natural: la evolución no avanza hacia formas más perfectas, sino formas más adecuadas para la adaptación. 'Perfección' es un concepto metafísico que no tiene cabida en la biología evolutiva.
} 
complejo. El terreno de la informática, señala Paulos, ofrece gran cantidad de casos en los que se producen estructuras complejas a partir de algoritmos simples.

Ahora bien, el concepto de 'diseño' es sumamente problemático. Básicamente, la discusión acerca del DI se centra en los criterios que se requieren para identificar ciertos rasgos en un objeto determinado como resultado de un agente. Hume (1988, p. 171ss), ya había encarado este problema, y para presentarlo, parte de una comparación entre el diseño de los objetos artificiales y naturales como producto de la deidad. El filósofo encuentra que hay una disparidad en la analogía. Por una parte, en las producciones humanas es posible inferir su diseño a partir de las experiencias acumuladas, del conocimiento previo que se tiene de las habilidades y destrezas del hombre. Partiendo de estas numerosas experiencias acumuladas que tenemos de las acciones humanas y sus productos, argumenta Hume, podemos establecer toda clase de inferencias acerca de su diseño.

Mas, por otro lado, a las presuntas obras del Creador no se puede aplicar el mismo criterio: "La deidad nos es conocida sólo por sus obras, y es un ser único en el universo, no incluido bajo cualquier especie o género, de la experimentación de cuyos atributos o cualidades podemos inferir cualquier atributo o cualidad en ella" (Hume, 1988, p. 171). Si presumimos que un objeto es resultado de la acción humana, es por las experiencias que tenemos acerca de las acciones humanas, pero no tenemos semejantes experiencias respecto del Ser Supremo. Para saberlo, tendríamos que tener alguna clase de conocimiento, por lo menos aproximado, del supuesto Creador.

Algunos partidarios del DI argumentan que no es necesaria ninguna clase de información acerca de la naturaleza del Diseñador. Del Ratzsch, tras considerar como programas científicos legítimos las suposiciones de que la vida terrestre pudo ser resultado de experimentos de inteligencias alienígenas, señala lo siguiente:

Debería ser evidente que la identidad de cualquier diseñador es irrelevante para las consideraciones anteriores. Olvidados ingenieros biológicos del ser humano, alienígenas tecnológicamente avanzados, o lo que sea -no es necesaria ninguna diferencia fundamental para una investigación genuinamente científica del objeto en cuestión. Y esto vale para cualquier diseñador, sea sobrenatural o no. Un dominio que exhibe las propiedades 
necesarias para ser un dominio de la investigación científica puede apoyar dicha investigación, independientemente de la forma en la que llegó a tener esas características (Ratzsch, 2010, p. 348) (La traducción es mía).

Más adelante, el autor sostiene que también es irrelevante indagar acerca del propósito o la finalidad del presunto diseño. En otras palabras, lo que el autor sugiere es que podemos inferir que un objeto determinado es resultado de un diseño, pero sin información acerca del diseñador o la finalidad del objeto. Sin duda, la ciencia ha avanzado suponiendo "cajas negras" (por ejemplo, el éter que permitía explicar la propagación de la luz a las teorías ondulatorias), pero se asumían como "causas supuestas" que nos dan una explicación hipotética del fenómeno y que investigaciones posteriores esclarecerán o refutarán (como ocurrió, efectivamente, con el éter); esto es, la "caja negra" funciona como una explicación causal hipotética. Mas el planteamiento de Ratzsch es muy diferente: una "caja negra" para una explicación teleológica, en la que, además, se asume que la “caja negra” no será esclarecida, ni es importante hacerlo. Si es así, parece no haber necesidad de apelar a la "caja negra" ya que no esclarece nada en absoluto.

Pero podría plantearse el problema desde un ángulo muy diferente. Tal vez la pretendida marca del diseño inteligente resulta de tomar como referencia al propio ser humano y su capacidad de diseñar y construir objetos. En este sentido, el razonamiento de Hume da a entender que toda consideración acerca de diseños no humanos en la Naturaleza no representa más que proyecciones antropomórficas ${ }^{7}$. Esto quiere decir el ser humano podría proyectar sus propias cualidades cuando pretende explicar un objeto como resultado de un diseño no humano. Podríamos parafrasear lo anterior mediante el siguiente argumento:

1) El hombre, siendo un ser inteligente, diseña objetos complejos.

2) En la Naturaleza se hallan objetos complejos.

3) Por tanto, los objetos complejos de la Naturaleza son resultado de un diseño de un ser inteligente.

\footnotetext{
7 Para un análisis detallado, ver Ayala 2010, p. 368.
} 
Sin embargo, este argumento es insostenible, porque del hecho de que la inteligencia humana sea capaz de producir objetos complejos, no se sigue que todo objeto complejo sea resultado de la acción de un ser inteligente. Se trata de una analogía falaz, pues están descartadas otras posibilidades (como el hecho de que los objetos complejos puedan evolucionar sin intencionalidad o propósito de un ser inteligente).

Llegados a este punto, convendría preguntar en qué sentido se habla de 'diseño'. Los científicos podrán utilizar el término 'diseño' en un sentido metafórico para designar determinados fenómenos o entidades, por lo que no es de extrañarse que se hallen en la literatura científica expresiones como 'diseño de las moléculas', 'diseño de los organismos', 'arquitectura de las galaxias', etc. Se trata de metáforas que no necesariamente implican que tales entidades o fenómenos sean el producto premeditado de un Diseñador. Pero en el léxico neocreacionista, el término 'diseño' no es empleado de este modo.

En todo caso, es válido preguntar si el 'diseño' en un sentido literal pueda tener algún valor para la ciencia: ¿cómo se podrían reconocer patrones que nos lleven a inferir algún tipo de diseño no humano? ¿De qué forma se podrían evitar las connotaciones antropomórficas? ¿Qué utilidad tendría para la ciencia? Tales preguntas permanecen abiertas. No obstante, se puede afirmar, al menos, que la investigación científica desde Darwin ha avanzando prescindiendo de toda consideración teleológica o apelación alguna a "diseños inteligentes".

En resumen, el panorama del DI es el siguiente: una complejidad que no es improbable y que es dudosamente irreductible, un presunto diseño que no nos da pistas para su identificación, y un Diseñador que permanece como una incógnita. Por ende, estamos ante una teoría que no resiste la evaluación crítica. Pero hay algo más que apuntar.

Como señalé al inicio de este apartado, la queja principal de los defensores del DI hacia la teoría de la selección natural consiste en que ésta excluye por completo las explicaciones sobrenaturales, proporcionando una explicación de la evolución apoyada en causas naturales. En particular, el asunto del azar -que no es el factor decisivo en el proceso evolutivo, pero pretenden 
presentarlo como si lo fuese- es su principal blanco. $Y$ en la medida en que el programa evolucionista tiene aún ciertas lagunas, éstas son presentadas como obstáculos insalvables.

En gran medida, la argumentación del DI se sostiene en la pretendida incapacidad de la biología evolutiva de explicar la vida en términos naturalistas. Y partiendo de esta supuesta incapacidad, se introduce la idea del 'diseño': “La biología evolutiva es incapaz de explicar la formación de X estructura, luego, es resultado de un diseño"; "la vida no puede ser resultado de causas fortuitas, luego, es resultado de un diseño", y así sucesivamente. Esta forma de proceder es falaz, pues se trata de apelación a la ignorancia (argumento ad ignorantiam) que, en este caso, se formularía así: asumiendo que la teoría de la selección natural no explica con todo detalle la evolución, los impulsores del DI lo toman como evidencia positiva a favor de su teoría. Pero la ausencia de prueba no constituye prueba de ausencia, pues los detalles podrían ser esclarecidos en el futuro. Aun si la Síntesis Moderna fracasara en su intento de explicar cabalmente el proceso evolutivo, podrían surgir teorías alternativas que no necesariamente tendrían que recurrir a causas sobrenaturales o a la teleología -v.gr., el "Principio Omega" de Theillard de Chardin-.

Como toda empresa científica, la teoría de la selección natural está abierta a la falsación. Mas la teoría del DI no representa una objeción seria contra la teoría científica de la evolución. Y no sólo por la ausencia de pruebas empíricas a su favor o sus intentos de refutación mediante argumentos de "hombre de paja". El DI está en una situación más complicada porque enfrenta un problema teórico mayor, que no preocupa en lo absoluto a la biología evolutiva. Si los defensores del DI pretendieran evitar el argumento ad ignorantiam deberán presentar pruebas positivas en pro de sus hipótesis. Para ello, no sólo requerirían esclarecer el confuso término de 'diseño' y probar su eficacia teórica, sino que tendrán que demostrar -y esto es lo más problemático- la existencia del supuesto Diseñador. Trátese de inteligencias extraterrestres, trátese de un Ser Supremo recordemos que para Ratzsch las diferencias entre entidades tan dispares no es relevante-¿cómo puede demostrarse su existencia? ¿Qué observaciones o qué procedimientos experimentales podrían corroborarla? El panorama, visto así, se ve más complicado para los partidarios del DI. 
Al no tener semejantes compromisos metafísicos, la teoría de la selección natural se presenta como una teoría más simple, y la navaja de Ockham la favorece. Pero surge ahora la cuestión de qué otra clase de compromisos metafísicos podría tener (o se le podrían atribuir a) esta teoría. De ello nos ocuparemos enseguida.

\section{Ateísmo y ciencia.}

Es momento de ver ahora la otra cara de la moneda. Muchos teóricos consideran que la teoría de la evolución autoriza negar la existencia de Dios u otras entidades sobrenaturales. Al abrir camino a una explicación científica y naturalista del origen de la vida -apoyada en los descubrimientos astrofísicos del origen del Universo- parece seguirse la falsedad de la "hipótesis Dios".

Sin embargo, es indispensable preguntar en qué sentido tal hipótesis es rechazada. Puede significar simplemente que carece de relevancia explicativa, sin aseverar nada en términos ontológicos: podría haber alguna clase de deidad, aunque no se requiere apelar a su existencia para explicar la Naturaleza ${ }^{8}$. O puede significar que los resultados de la biología evolutiva, la astrofísica y otras ciencias nos dan argumentos de peso para rechazar la creencia en cualquier Ser Supremo o Diseñador Inteligente.

¿Cómo podría argumentarse la segunda opción? Si se declara que Dios no existe sobre la base de que no se ha demostrado su existencia, se está incurriendo nuevamente en el argumento ad ignorantiam. Para evitar semejante falacia, podría establecerse que las ciencias nos dan los suficientes elementos que nos permiten restar credibilidad a cualquier afirmación acerca de su existencia.

Así lo propone Dennett y lo plantea en los siguientes términos:

La perspectiva darwiniana no prueba que Dios - en cualquiera de estas formas - no podría existir, sólo que no tenemos ninguna buena razón para pensar que Dios existe. Entonces, no

\footnotetext{
8 Darwin siempre evitó cualquier afirmación al respecto, pese a las presiones de Huxley y Aveling (Price, 2010). Desde luego, era consciente que su teoría conmocionaba los fundamentos de los sistemas religiosos. Sin embargo, la precaución de Darwin de pronunciarse deliberadamente a favor del ateísmo bien podría haber obedecido a ser consecuente con sus aspiraciones científicas y limitarse a afirmar lo que pudiera ser verificable. El agnosticismo, al cual parece haberse adherido en algún momento de su vida, sería una muestra de ser consecuente con su actividad como científico.
} 
es un clásico argumento de reducción al absurdo, sino más bien, es un desafío racional que reduce las opciones de los creyentes a una base minimalista absurda (Dennett, 2007. P. 147) (La traducción es mía).

En Carl Sagan y Ann Druyan encontramos una postura más moderada al respecto: "La evolución no supone en forma alguna el ateísmo, aunque es consecuente con el ateísmo" (Sagan y Druyan, 1993, p. 73). Posteriormente, ambos autores apuntan que el principal conflicto de la evolución es con los relatos creacionistas de las religiones, pero no establece ningún veredicto acerca de la negación de dios alguno.

Pero cabe preguntar si es válido pasar lógicamente de la afirmación “La 'hipótesis Dios' no es relevante" a "No hay ningún Dios". Si la investigación científica adopta resueltamente una perspectiva naturalista, tenemos el problema de intentar extraer inferencias de algo que pretendidamente está más allá de la propia Naturaleza. Visto así, ¿se puede establecer un veredicto acerca de la inexistencia de entidades sobrenaturales?

Dawkins, en el mismo tenor que Dennett, acepta la imposibilidad de negar categóricamente la existencia de Dios. No obstante, sugiere que la cuestión hay que ponerla en términos de probabilidades (Dawkins, 2006, p. 50ss). Para ello, el biólogo británico propone una escala donde el número 1 representaría el 100\% de probabilidades de que hay un Dios, y el 7 representaría el 100\% de probabilidades de que no hay un Dios. Sobre esta base, asume que no hay modo de sostener con plena certeza el número 7 de la escala; mas existen, en su opinión, suficientes elementos para afirmar una posición de "más del 50\%" de probabilidades de la inexistencia de Dios. Evidentemente, traducir el problema al lenguaje de las probabilidades no resulta muy útil, pues abre la cuestión de cómo especificar los valores de semejante escala. La propuesta tendría que complementarse con alguna clase de test mediante el cual se pueda evaluar una creencia y asignar los valores respectivos. No obstante, esto serviría únicamente para establecer una tipología de creencias, no para resolver el problema en cuestión. ¿Qué razones podrían formularse para justificar los valores de "más del 50\%" de probabilidades de la inexistencia de Dios? 
El recurso a la 'carga de la prueba' podría de ser de útil para resolver el problema. Dawkins (2006, p. 53) recurre a ella, afirmando que la carga de la prueba recae en los creyentes, no en los detractores. Mas es pertinente hacer algunas aclaraciones. El principio de la carga de la prueba ("quien afirma la verdad de un enunciado está obligado a probarla") es fundamental en la metodología de las ciencias, el derecho y otras disciplina, pues permite asignar los compromisos argumentativos a los participantes de las polémicas. Así, si un individuo pretende postular una hipótesis original o una nueva teoría, entonces está obligado a presentar las pruebas respectivas, y no sus detractores.

Por ello, hay algo de razón en lo que sostiene Dawkins: la carga de la prueba, en efecto, les corresponde a los creacionistas en tanto que son ellos quienes sostienen la existencia de un Diseñador del Universo. Sin embargo, si éstos no presentan evidencias que respalden tal afirmación, sólo significa que se carecen de evidencia que la respalde, pero su valor de verdad queda indeciso. Si se pretende, por otra parte, llegar la conclusión de que no hay un Diseñador sobre la base de que los creacionistas no ofrecen pruebas satisfactorias, se incurriría, una vez más, en el argumento ad ignorantiam. Por lo tanto, la apelación a la carga de la prueba únicamente sirve para obligar a las partes a presentar los argumentos que apoyan a sus respectivas posturas porque, en caso de incumplirla o deslizarla al oponente, solo se podría señalar que una de las partes no está procediendo adecuadamente en términos argumentativos ${ }^{9}$.

Pero es en este punto donde nos topamos con el problema lógico de los existenciales negativos: la falta de evidencia a favor de la existencia de una entidad hipotética no nos autoriza a negarla categóricamente. Paulos (2009) lo expone del siguiente modo: “...las proposiciones existenciales que afirman la existencia de una entidad no matemática con cierta propiedad (o conjunto de propiedades no contradictorias) nunca puede descartarse de manera concluyente" ( $p$. 57). Según este autor, ni siquiera podríamos negar una aseveración existencial de una entidad altamente improbable tal como 'Existe un perro que habla inglés por el trasero', porque "no podemos escudriñar hasta el último rincón para afirmar con absoluta confianza que no existe

\footnotetext{
${ }^{9}$ Claro está, el ateo podrá señalar atinadamente que si el creacionista no justifica su postura o evade la carga de la prueba, ésta no merece ser tomada en serio.
} 
ninguna entidad con la propiedad en cuestión" (p. 57). Si no es posible aseverar la inexistencia de una entidad hipotética, ¿cómo podría probarse la inexistencia de Dios u otras entidades hipotéticas (como los fantasmas, los duendes o los seres de las distintas mitologías)?

Sin pretender presentar una solución al problema de los existenciales negativos, creo que podría haber una posible salida si introducimos algunos operadores modales en los argumentos. Conviene, en primera instancia, recordar la distinción en lógica modal entre 'necesidad' y 'posibilidad'. En una proposición de necesidad ('Es necesario que P'), el valor de verdad está plenamente aseverado y no es el caso que la proposición pueda ser falsa -o en otras palabras, es verdadera en todos los mundos posibles-. Por otro lado, en una proposición de posibilidad ('Es posible que $\mathrm{P}^{\prime}$ ), el valor de verdad está sujeto a la contingencia, esto es, podría ser verdadera, al menos, en un mundo posible. De este modo, la diferencia entre (1) 'Juan Gabriel no murió' y (2) 'Tal vez Juan Gabriel no haya muerto' estriba en que la primera asevera que la muerte del Divo de Juárez no ocurrió, mientras que la segunda lo afirma de forma hipotética.

Esto tiene consecuencias para la argumentación. Argumentar a favor de (1) exige presentar evidencia concluyente que nos permita enunciarla asertivamente (en este caso, un conjunto de datos que demuestren fehacientemente que el cantante sigue vivo). En cambio, dada la naturaleza conjetural de (2), podemos ofrecer algunos datos que respalden la plausibilidad de la hipótesis (por ejemplo, presentar ciertas razones que apoyen la hipótesis: las extrañas circunstancias de su muerte, ciertas contradicciones en los documentos funerarios, etc.). En consecuencia, el compromiso argumentativo en pro de (1) es mayor que el de (2).

Retornando al asunto que nos ocupa, una posible estrategia para salir del atolladero de los existenciales negativos sería argumentar la plausibilidad de la inexistencia de entidades hipotéticas. En principio, la estrategia estaría orientada a probar que tales entidades de dudosa existencia no contribuyen, en modo alguno, a ampliar nuestro conocimiento del mundo. Si consideramos que los avances científicos nos proporcionan explicaciones de un gran número de fenómenos, incluida la vida, sin requerir de la "hipótesis Dios", esto permitiría inferir la irrelevancia de tal hipótesis. El argumento podría ser así: 
1.- Si es posible una explicación meramente naturalista del Universo, entonces es posible que no sea necesaria una explicación teológica.

2.- Es posible una explicación meramente naturalista del Universo.

Por tanto,

3.- Es posible que no sea necesaria una explicación teológica.

En la medida en que la premisa 2 sea verdadera (lo cual dependerá del desarrollo de la investigación científica), se podría, como sugiere Dennett, reducir la teología a esa "base minimalista absurda". En todo caso, este argumento sólo justificaría la postura de que la teología no tendría cabida en la ciencia y no representa un contundente serio frente a las explicaciones naturalistas. Para justificar que la hipótesis divina no es plausible, tendría que formularse un segundo argumento:

1.-Si es posible que no sea necesaria una explicación teológica del Universo, es posible que no hayan razones para admitir la existencia de un Ser Supremo.

2.- Es posible que no sea necesaria una explicación teológica del Universo.

Por tanto,

3.- Es posible que no hayan razones para admitir la existencia de un Ser Supremo.

Como puede apreciarse, este argumento se sostiene sobre el anterior. Lo que propone es una cierta versión del ateísmo, que algunos denominan agnosticismo ateo o ateísmo débil, que se justificaría sobre la base de la irrelevancia de la explicación teológica. Este argumento no incurriría en la falacia ad ignorantiam, ya que al no ser la conclusión plenamente asertiva, no se están excluyendo otras posibles conclusiones - recordemos que esta falacia es, en el fondo, un tipo de falso dilema-. En todo caso, el argumento intentaría sostener que las creencias teológicas no están justificadas o suficientemente justificadas ${ }^{10}$.

\footnotetext{
${ }^{10}$ Se podrá objetar que lo que he planteado coincide exactamente con Dawkins y su escala. Tal vez así sea, porque los valores probabilísticos son un medio para dar cierta confianza en el campo incierto de la posibilidad.
} 
Volviendo ahora a la pregunta: ¿se infiere el ateísmo de la teoría de la evolución? ¿O de la ciencia en general? La respuesta más adecuada, en mi opinión, sería: si bien no es posible determinar con certeza la inexistencia del Diseñador, los resultados de la ciencia nos dan ciertos elementos para inclinarlos por la posibilidad de que tal entidad no existe. Es decir, no podemos negar categóricamente que Dios exista, pero tampoco tenemos suficientes razones para creer en Él.

\section{Conclusiones.}

Por lo general, las polémicas entre ateos y creyentes son discusiones viciadas. Esto se debe no sólo a que se trata de posiciones diametralmente opuestas, sino que en unos y otros suelen asumir que sus creencias están fundadas en cierto grado de certeza. Lo que he intentado mostrar es que, si el ateísmo o el agnosticismo están basados en la ciencia -a diferencias de otros ateísmos, como el propuesto por Comte-Sponville (2006) o los nietzscheanos-, se debe asumir la actitud mesurada de la ciencia: no aseverar nada si no se posee suficiente evidencia. Entonces, un agnosticismo ateo podría ser la postura más acorde al espíritu naturalista de la ciencia y más consistente en términos lógicos.

Entiendo que esta propuesta no sea del todo convincente para muchos ateos. En muchas personas existe la fuerte necesidad de aseverar categóricamente sus propias creencias, y más si éstas están arraigadas por motivaciones psicológicas. El ateísmo puede ser adoptado por múltiples motivos, como el resentimiento contra la religión o por expectativas políticas o sociales. Como sea que se llegue a adoptar una creencia, lo único que quiero enfatizar es que debería estar sustentada en razones más que en motivos. Y si algo debería distinguir al no creyente del creyente debería ser justamente esto.

Para finalizar, debo destacar que muchos cabos han quedado sueltos en el presente escrito. No me he adentrado en el problema de los tipos de conocimiento -saber, creer, fe, etc.-, ni en la cuestión de los grados de certeza. He abordado de forma muy somera el problema filosófico de la existencia, que es, en gran medida, lógico, semántico y epistemológico. Y las conclusiones que he 
extraído se han basado en algunas posturas y algunos argumentos; por ende, no pueden considerarse como definitivas. Reservo para el futuro un tratamiento más exhaustivo de éstos y otros problemas metafísicos

\section{Referencias}

Ayala, F. (2010). "There is no place for Intelligent Design in Philosophy of Biology" en Francisco Ayala y

Robert Arp (ed.), Contemporary Debates in Philosophy of Biology, Londres: Blackwell Publishing.

Behe, M. (2004). "Irreducible complexity: Obstacle to Darwinian evolution", en William Dembski y Michael

Ruse (Eds.), Debating design: From Darwin to DNA. Nueva York: Cambridge University Press.

Comte-Sponville, A. (2006). El alma del ateísmo. Una introducción a una espiritualidad sin Dios, Barcelona:

Ediciones Paidós.

Cronin, H. (1991). The ant and the peacock. Altruism and sexual selection from Darwin to today, Cambridge:

Cambridge University Press.

Darwin, C. (2010). El Origen de las Especies, México: Grupo Editorial Éxodo.

Dennett, D. (2007). “Atheism and Evolution” en Michael Martin (ed.), The Cambridge Companion to Atheism,

Cambridge: Cambridge University Press.

Dawkins, R. (1993). El Relojero Ciego, Barcelona: RBA Editores.

Dawkins, R. (2006). The God Delusion, Nueva York: Houghton Mifflin Company.

Eldredge, N. (1997). Síntesis inacabada. Jerarquías biológicas y pensamiento evolutivo moderno, México:

Fondo de Cultura Inacabada.

Glock, H-J. (2012). ¿Qué es la filosofía analítica? Madrid: Tecnos.

Hume, D. (1988). Investigación sobre el entendimiento humano, Madrid: Alianza Editorial.

Kant, I. (2009). Crítica de la razón pura, México: Fondo de Cultura Económica/UAM/UNAM.

Koyré, A. (2005). Del mundo cerrado al universo infinito, México: Editorial Siglo XXI.

Maturana, Humberto y Francisco Varela, De máquinas y seres vivos. Autopoiesis: Ia organización de lo vivo, Santiago de Chile: Editorial Universitaria.

Mayr, E. (1992). Una larga controversia. Darwin y el darwinismo. Barcelona: Editorial Crítica.

Monod, J. (1981). El azar y la necesidad. Ensayo sobre la filosofía natural de la biología moderna, Barcelona:

Tusquets. 
Nowinski, C. (1979). “Biología, Teorías del Desarrollo y Dialéctica” en Jean Piaget (ed.): Tratado de lógica y conocimiento científico, T. 5: Epistemología de la Biología, Buenos Aires: Ediciones Paidós.

Paley, W. (1802). Natural Theology or, Evidences of existence and attributes of Deity collected from the appearances of Nature, edición electrónica.

Paulos, J.A. (2009). Elogio de la irreligión, México: Tusquets.

Pievani, T. (2006). Creación sin Dios, Madrid: Ediciones Akal.

Price, B. (2010). Charles Darwin. La polémica de los orígenes, México: Tomo Editorial.

Ratzsch, Del 2010, "Theres is a place for Intelligent Design in Philosophy of Biology" en Francisco Ayala y Robert Arp (ed.), Contemporary Debates in Philosophy of Biology, Londres: Blackwell Publishing.

Ruse, M. (1990). La filosofía de la biología, Madrid: Alianza Editorial.

Sagan, C. y Druyan, A. (1992). Sombras de antepasados olvidados, Barcelona: Editorial Planeta. 